\title{
FEMALE GENITAL TUBERCULOSIS AS A CAUSE OF PRIMARY AMENORRHEA IN A YOUNG UNMARRIED WOMAN.
}

\author{
Zende Prashant Padmakar ${ }^{1}$, Aher Gautam² ${ }^{2}$ Dandavate $\mathrm{K}^{3}$
}

1. Assistant Professor, Department Of OBGY, Padmashree Dr. Vithalroa Vikhe Patil Medical College \& Hospital ,Near Govt. Milk Dairy, Vilad Ghat, Ahmednagar, Maharashtra.

2. Professor, Department Of OBGY, Padmashree Dr. Vithalroa Vikhe Patil Medical College \& Hospital ,Near Govt. Milk Dairy ,Vilad Ghat, Ahmednagar , Maharashtra.

3. Resident, Department Of OBGY, Padmashree Dr. Vithalroa Vikhe Patil Medical College \& Hospital ,Near Govt. Milk Dairy, Vilad Ghat, Ahmednagar, Maharashtra.

\section{CORRESPONDING AUTHOR:}

Dr.Zende Prashant Padmakar,

Zende Hospital, Tarakpur Bus Stop Road,

Ahmednagar- 414001, Maharashtra State.

E-mail: manjirizende@gmail.com

ABSTRACT: Primary Amenorrhea is defined as 1)No periods by age 14 in the absence of growth or development of secondary sexual character.2)No periods by age 16 regardless of the presence of normal growth \& development with the appearance of secondary sexual characters.

Incidence of Extrapulmonary TB(EPTB)is increasing in young women throughout the world. We report a case of young woman apparently having no sings \& symptoms of Tuberculosis.

CASE REPORT:-18 years young female patient was referred to us as a case of Primary Amenorrhea.She had Normal secondary sexual characters \& normal Breast Development(Tanner staging of Breast-IV.)She had negative Progesterone Challenge Test (PCT).Estrogen \& Progesterone Challenge Test was negative. Diagnosis of End Organ Problem was done. Diagnosis of Genital Tuberculosis was confirmed by Hysterolaparoscopy. She was given AKT for six months. Now she has positive Progestogen Challenge Test. DISCUSSION: Hysterolaparoscopy is important investigation in a case of Primary Amenorrhea with negative Estrogen \& Progesterone Challenge Test. Counseling is necessary in unmarried young woman for Minimally Invasive procedure like Hysterolaparoscopy. Short Chemotherapy has found to useful for FGTB.

KEYWORDS:-Primary Amenorrhea, Genital Tuberculosis

\section{INTRODUCTION:}

\section{Primary Amenorrhea is defined as}

1) No periods by age 14 in the absence of growth or development of secondary sexual characteristics.

2) No periods by age 16 regardless of the presence of normal growth \& development with the appearance of secondary sexual characteristics ${ }^{1}$

Incidence of primary amenorrhea in gynecological practice is less than $5 \% .^{2}$

Incidence of primary amenorrhea due to genital TB is $2.5 \% .^{3}$

Primary Amenorrhea due to Female Genital Tuberculosis though very rare it is treatable. 
Although Pulmonary TB (PTB) remains the commonest infectious type of TB, Extrapulmonary TB(EPTB)is being increasingly encountered specially in young women throughout the world ${ }^{4}$

CASE REPORT: 18 years young female patient was referred to us as a case of Primary Amenorrhea. On examination patient was well built. Her Height was $1.65 \mathrm{mt} \&$ Weight was $66 \mathrm{~kg}$. Her BMI was 24.26. She was overweight. Her secondary sexual character s were well developed. She had normal Breast Development

(Tanner staging of Breast-IV). She had pubic \& axillary hair.

Her routine hematological investigation like Haemogram, Random Sugar , ESR were Within Normal Limits. Her Pelvic USG was normal. Her external genital examination revealed no abnormality. She being unmarried, PS-PV examination was not carried out. Her P R examination was carried out. Uterus was felt per rectally. Her hormonal investigation like TSH, Prolactin were normal. She was given Progesterone Challenge Test (PCT) i.e. Oral MPA - 10mg was given BID for five days. She had no withdrawal bleed. Since she had no withdrawal bleed; Estrogen \& Progestin Challenge Test challenge test was given i.e. Conjugase Estrogen was given in dosage- $2.5 \mathrm{mg}$ for 21 days followed by MPA for last 10 days dosage of $10 \mathrm{mg}$ OD. She had no withdrawal bleed. To Confirm diagnosis second course of Estrogen \& Progesterone challenge test was given. Her Diagnosis of end organ problem was confirmed. She being unmarried, minimal invasive procedure of Video Endoscopic Hysterolaparoscopy was planned. Counseling was necessary because she was young, unmarried well built woman from rural area.

\section{FLOW CHART}

Amenorrhea

TSH, Prolactin, PCT

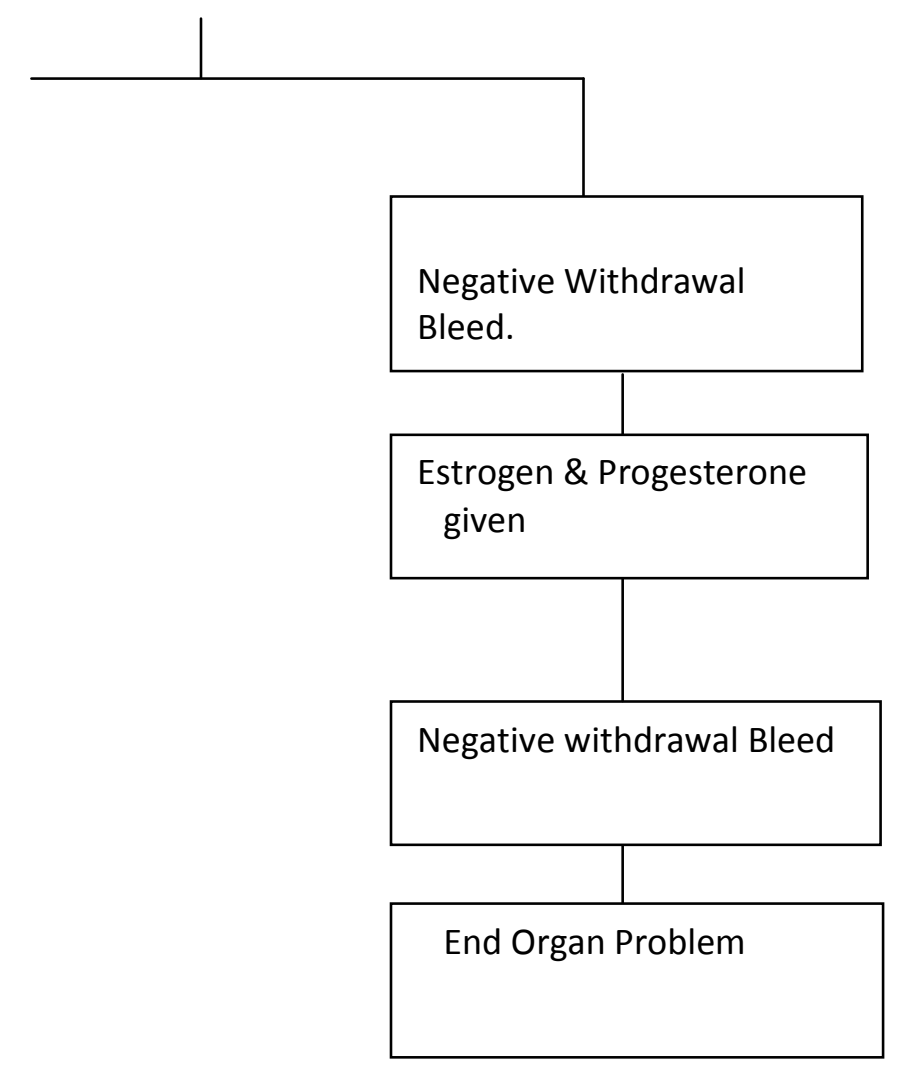




\section{On Hysteroscopy}

-She had irregular cavity,

-There were no adhesions.

-Both ostia were visualized.

-D \& C was done for Endometrial TBPCR.

\section{On Laparoscopy}

-Her uterus was of normal size \& shape.

-she had both tubes congested \& edematous \& adherent to ovaries.Tubercles were not seen(Figure 2 \& 3)

-She had omental adhesions.

-She had adhesions present in POD \& Lateral Pelvic wall. Omental Adhesions were present to parietal wall. Omental Adhesions were released.(Figure.4)

-All these findings were s/o Female Genital TB.

-She had perihepatic adhesions s/o Fitz Hugh Curtis syndrome.5 \& 6 \&8.(Figure.1)

-Chromopertubation was done with Methylene Blue. There were bilateral Fimbrial Tubal Block.

-Diagnosis was confirmed by Positive TBPCR report.

-She was given six months AKT.

-AKT 4 was given for two months \& AKT -3 was given for 4 months.

-Now she is having withdrawal bleed after Progestin challenge test .Now she is regularly menstruating.

DISCUSSION: A case of primary Amenorrhea needs proper \& Methodological evaluation. Compartment wise diagnosis is made by proper Methodological approach. For Etiological diagnosis Hysterolaparoscopy is important Investigation. USG has very limited role on Diagnosis of Genital TB. ${ }^{6}$ In unmarried case, especially in rural class it is difficult to convince the patient $\&$ parents for Hysterolaparoscopy. Other than primary Amenorrhea, there were no signs \& symptoms of Female Genital TB. Various types adhesions may be present in genital TB covering Genital Organs with or without Omentum \& Intestines. There is a very High prevalence (48\%) of peri Hepatic Adhesions on laparoscopy in FGTB cases (Figure.1) 5 \& \& 8. Diagnosis of FGTB was confirmed by POSITIVE TBPCR.

Early marriage without investigation \& treatment poses problem in that family. Hence there is a role of Methodological approach in investigating in a case of Primary Amenorrhea. Multiple drug treatment in adequate dosage \& duration is the main stay of treatment including FGTB. Short course Chemotherapy has found to be useful for FGTB 9.

CONCLUSION:-Primary Amenorrhea is Important Gynecological, Endocrinological condition. Compartment wise diagnosis is made by proper Methodological approach. High Index of Suspicion is required as many cases can be asymptomatic in early stages. Hysterolaparoscopy is important investigation to diagnose Female Genital Tuberculosis. Short Chemotherapy is useful for the same.

\section{REFERENCES:-}

1. Leon Speroff, Robert H Glass \& Nathan G. Kase - Clinical Gynecologic Endocrinology \& infertility fourth Edition. -5 Amenorrhea 165-211 
2. Wachtel SS The genetics of intersexuality: Clinical and theoretic Perspectives. Obstet Gynecol 1979; 54:671-83.

3. Rao K, Pillai NV .Primary Amenorrhea (analysis of 40 cases) J Indian Medi Assoc 1991;89:42-43

4. Kumar S. Female genital Tuberculosis. In: Sharma SK Mohan A. (eds) Tuberculosis, 2nd Edition. Delhi; Jaypee, 2009; 441-8.

5. Sharma JB, Malhotra M, Arora R.Fitz -Hugh -Curtis Syndrome as a result of genital tuberculosis: as a report of three cases. Acta Obstet Gyneco Scand 2003; 82:295-7.

6. Sharma JB. Tuberculosis and obstetric and gynecological practice In Studd J, Tan SL Chervenak FA, (editors), Progress in Obstetric \& Gynecology Philadephia: Elsevier 2008; 18:395-427.

7. John Studd, Seang Lin Tan, Frank A. Cahrvenak. Current Progress in Obstetrics \& Gynaecology, Volume-1, Tuberculosis in Obstetrics and Gynecological Practice-18: J.B.Sharma :304-24.

8. Sharma JB Roy KK, Gupta N, et al. High Prevalence of Fitz-Hugh-Curtis Syndrome in genital tuberculosis. Int J Gynecol Obstet 2007; 99:62-3.

9. Arora R, Rajaram P. Oumachigui A, et al. Prospective Analysis of short course Chemotherapy in female genital tuberculosis. Int J Gynaecol obstet 1992; 38:31-4.

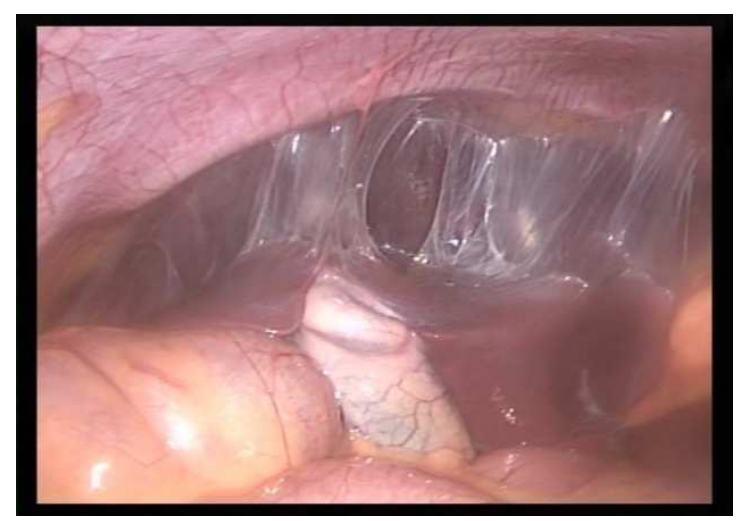

Fig 1: Laparoscopic findings showing perihepatic adhesions (Fitz Hugh Curtis Syndrome) in a proven case of genital tuberculosis

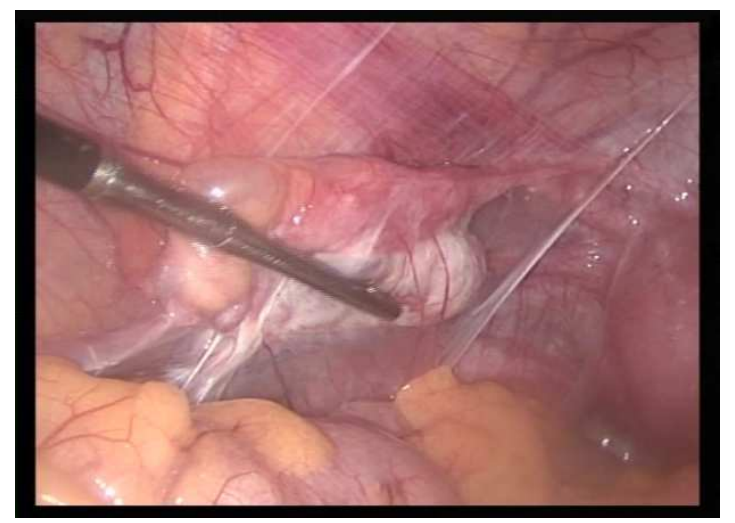

Fig.2 Laparoscopic findings showing right Tubo-ovarian mass. 


\section{CASE REPORT}

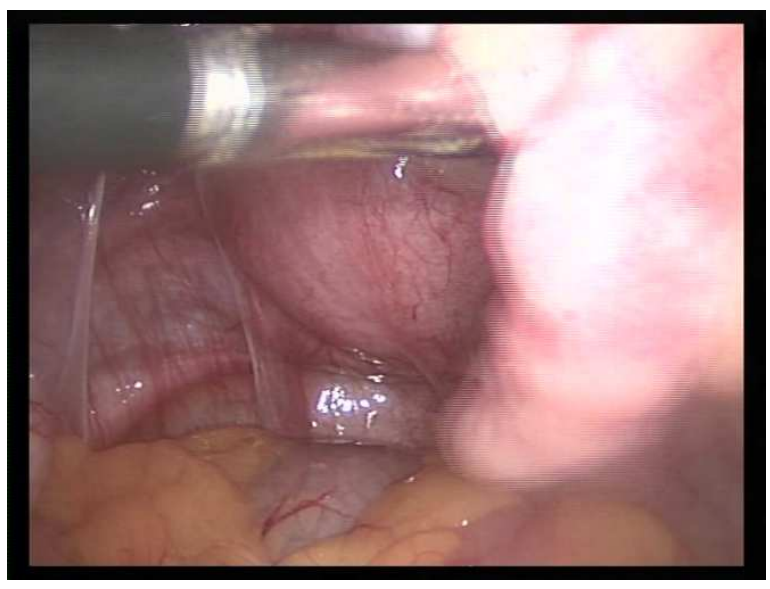

Fig 3: Left tube showing congestion and edema and hydrosalpinx.

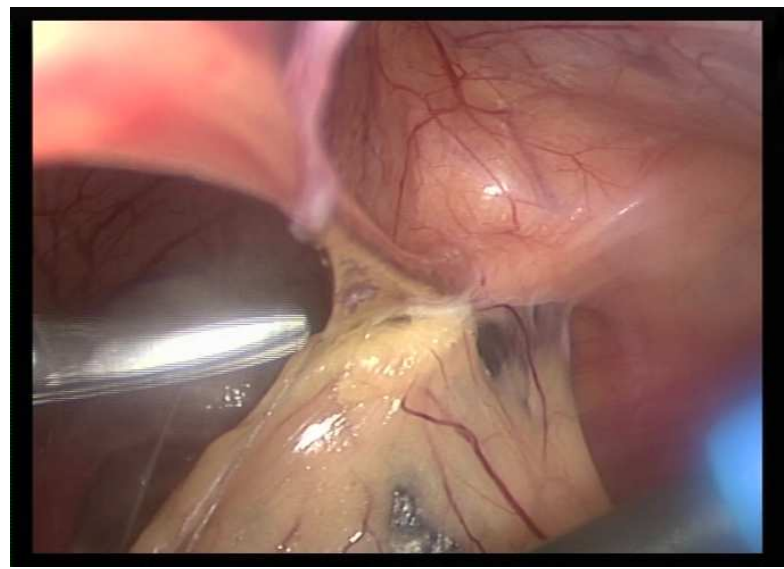

Fig.4: Omental adhesions to parietal wall are released . 